\title{
ANALISA PENGARUH PEKERJA SECARA MENTAL, GAJI, KESEMPATAN PROMOSI, KONDISI KERJA DAN KESESUAIAN PRIBADI PEKERJA TERHADAP KINERJA PEGAWAI PADA KANTOR PELAYANAN PAJAK MUARA TEWEH
}

\author{
Tania Jannah \\ Sekolah Tinggi Ilmu Ekonomi Pancasetia Banjarmasin \\ Jl. Ahmad Yani Km. 5.5 Banjarmasin \\ taniajannah1818@gmail.com
}

\begin{abstract}
Abstrak :Tania Jannah, Pengaruh pekerja secara mental, gaji, kesempatan promosi, kondisi kerja dan kesesuaian pribadi pekerja terhadap kinerja pegawai kantor pelayanan pajak muarateweh, Pembimbing Utama: Risadiro Cahyono Pembimbing Pembantu: Asruni

Penelitian ini bertujuan untuk menguji Analisa yang mempengaruhi kinerja pegawai kantor pelayanan pajak muara teweh. Permasalahan umum dalam penelitian ini adalah dimana kurangnya Pengaruh mental, gaji, kesempatan promosi, kondisi kerja dan kesesuaian pribadi pekerja terhadap Kinerja Pegawai Pada kantor pelayanan pajak muara teweh, dimana kinerja pegawai menurun sehingga peneliti perlu mengetahui pengaruh variabel mana yang mempengaruhi kinerja pegawai pada kantor pelayanan pajak muara teweh

Populasi dalam penelitian ini ialah 50 Pegawai Pada kantor pelayanan pajak muara teweh, data diambil dari kuesioner yang dibagikan kepada responden. Variabel dalam penelitian ini adalah variabel bebas (Independent) mental, gaji, kesempatan promosi, kondisi kerja dan kesesuaian pribadi pekerja sedangkan variabel terikatnya (dependent) adalah Kinerja Pegawai. Data dianalisis dengan menggunakan SPSS Versi 25.

Hasil penelitian menunjukkan bahwa Secara Simultan mental, gaji, kesempatan promosi, kondisi kerja dan kesesuaian pribadi pekerja berpengaruh signifikan terhadap kinerja pegawai kantor pelayanan pajakmuara teweh. secara parsial mental, gaji, kesempatan promosi, kondisi kerja dan kesesuaian pribadi pekerja berpengaruh signifikan terhadap kinerja pegawai pada kantor pelayanan pajak muara teweh.
\end{abstract}

Kata Kunci : mental, gaji, kesempatan promosi, kondisi kerja kesesuaian pribadi pekerja, kinerja pegawai

\section{Latar Belakang}

Keberhasilan suatu organisasi mencapai tujuannya tidak dapat dilepaskan kaitannya dengan faktor manusia yang merupakan kunci utama tercapainya sasaran organisasi. Manusia dimaksud di sini adalah sumber daya manusia yang berkualitas memiliki pengetahuan dan keterampilan, jujur bertanggung jawab serta memiliki sikap mental yang baik.

Tuntutan konsistensi terhadap sikap karyawan Kantor Pelayanan Pajak Muara Teweh diharapkan dapat mendukung pencapaian tujuan dan sasaran organisasi tidak mungkin dapat dicapai bilamana faktor-faktor yang berpengaruh terhadap tingkat kinerja karyawan tidak diterapkan pada organisasi tersebut.

Kinerja karyawan sebagai suatu sikap umum seorang individu terhadap pekerjaannya. Pekerjaan menuntut interaksi dengan rekan sekerja dan atasan, mengikuti aturan dan kebijaksanaan organisasi, memenuhi standar kinerja dan hal serupa lainnya. Ini berarti penilaian seorang karyawan terhadap betapa puas atau tidak puasnya dia akan pekerjaannya merupakan 
penjumlahan dari sejumlah unsur pekerjaan yang terpisahkan satu sama lain.

yang mendorong tingkat kinerja karyawan yang berkaitan dengan pekerjaan adalah; kerja yang secara mental menantang, ganjaran yang pantas, kondisi kerja yang mendukung, rekan kerja yang mendukung dan kesesuaian kepribadian pekerjaan. Namun dijelaskan pula bahwa konsep kinerja karyawan secara inheren (tertanam) begitu luas. Melihat pandangan yang dikemukakan oleh Stephen P. Robbins bahwa konsep kinerja karyawan itu sangat relatif dan begitu luas, mana penulis pada penelitian ini hanya akan melakukan pengujian terhadap variabel-variabel yang berkaitan dengan kinerja karyawan yang dikemukakan oleh Stephen P. Robbins dan peneliti lain. Variabel-variabel dimaksud adalah :

1. Kerja yang secara mental menantang, hal ini diukur sebab sering ada kecenderungan para karyawan lebih menyukai pekerjaan-pekerjaan yang sifatnya menantang yang memberi mereka.

2. Gaji dan insentif; karyawan lebih merasa terpuaskan bilamana mereka disamping mendapatkan gaji pegawai negerinya, mereka juga mendapatkan insentif lin seperti honor proyek, tambahan uang pakasi, uang jalan maupun tambahan insentif lain.

3. Kesempatan untuk promosi, karyawan sebelum menduduki jabatan tertentu,baik jabaan struktural maupun jabatan lainnya biasanya didahului oleh pendidikan penjengan ataupun pendidikan atau pelatihan-pelatihan lainnya. Hal ini yang kadang-kadang menjadi persyaratan, namun sering menjadi masalah pula kalau ternyata jabatan itu harus segera diisi, sementara karyawan yang memenuhi persyaratan tadi tidak tersedia,

4. Kondisi kerja: karyawan lebih senang
Dalam bukunya Stephen P. Robbins 1998, dikemukakan bahwavariabel-variabel bekerja dengan lingkungan kerja yang nyaman, bersih dan tidak berbahaya atau merepotkan, dekat dengan rumah, fasilitas sarana dan prasarana kantor memadai dan relatif modern.

5. Kesesuaian kepribadian pekerjaan; karyawan lebih suka akan pekerjaannya yang sesuai dengan latar belakang pendidikan, bakat yang dimiliki serta sesuai dengan keahlian dan pengalamannya selama mereka bekerja. Kenyataan menunjukkan bahwa produktivitas dan prestasi kerja karyawan kadang-kadang belum dicurahkan sepenuhnya sesuai kecakapan dan kemampuan yang dimilikinya.

Hal ini kemungkinan disebabkan oleh berbagai faktor baik yang bersifat internal maupun yang bersifat eksternal. Faktorfaktor yang menjadi penyebab adalah kurangnya kepuasan berupa pemberian gaji yang tidak seimbang, kurang penghargaan atas prestasi yang dicapai, kondisi kerja yang kurang baik, lingkungan kerja yang kurang kondusif, sarana dan prasarana kerja yang tidak memadai, kurangnya kesempatan mengikuti pendidikan, kurangnya kesempatan untuk promosi serta minimnya pemberian insentif.

Berdasarkan kondisi itulah, maka kinerja karyawan perlu mendapat perhatian yang sungguh-sungguh dari pimpinan organisasi, karena dapat mempengaruhi produktivitas, prestasi dan pencapaian tujuan organisasi, sehingga dengan kepuasan yang tinggi cenderung mendorong peningkatan produktivitas kerja pegawai ke arah yang lebih baik. Maka daripada itu penulis tertantang agar dapat melakukan penelitian dengan judul "Analisis Pengaruh Pekerja Secara Mental, Gaji, Kesempatan Promosi, Kondisi Kerja dan Kesesuaian Pribadi Pekerja terhadap 


\section{kinerja pegawai pada kantor pelayanan pajak muara teweh"}

\section{Landasan Teori \\ Pengertian Manajemen Sumber Daya Manusia}

Manajemen sumber daya manusia, disingkat MSDM, adalah suatu ilmu atau cara bagaimana mengatur hubungan dan peranan sumber daya (tenaga kerja) yang dimiliki oleh individu secara efisien dan efektif serta dapat digunakan secara maksimal sehingga tercapai tujuan (goal) bersama perusahaan, karyawan dan masyarakat menjadi maksimal. MSDM didasari pada suatu konsep bahwa setiap karyawan adalah manusia- bukan mesin dan bukan semata menjadi sumber daya bisnis.

\section{Teori Motivasi}

Dalam pemberian motivasi terhadap para karyawan yang terdiri dari berbagai budaya, maka seyogyanya seorang pimpinan organisasi mampu menguasai konsep tentang motivasi.

\section{Tinjauan Teoritis Tentang Organisasi}

Organisasi pada umumnya dapat dianggap sebagai sebuah sistem terbuka. Artinya dalam kenyataan organisasi itu adalah serangkaian kegiatan yang mempunyai tujuan umum dan untuk itulah terdapat keluaran dan masukan. Keluaran biasnaya akan merupakan produk dan jasa, sedang masukan akan berupa bahan baku,

\section{Metode Penelitian}

Jenis penelitian ini adalah penelitian korelasional (kuantitatif) yaitu penelitian yang dilakukan dengan cara mengumpulkan sejumlah data untuk melihat apakah terdapat suatu keterkaitan antara variabel bebas (independent) yaitu Mental (X1), Gaji (X2), Kesempatan Promosi (X3), Kondisi Kerja (X4) dan Kesesuaian Pribadi Pekerja (X5) uang, tenaga kerja dan sebagainya. Di dalam organisasi akan terdapat sub sistem untuk menangani strategi, kegiatan-kegiatan, serta susunan dan proses penunjang.

Setiap organisasi bersifat dinamis dan akan dipengaruhi sedikit banyak oleh perubahan-perubahan yang terjadi di lingkungan luar. Umpama, perubahan ekonomi akan mempengaruhi kinerja bisnis dan perubahan di dalam perundangundangan akan mempunyai dampak pada cara organisasi melakukan (Cushway dan Lodgem, 1995),

\section{Pengertian Kepuasan Kerja}

Perkembangan ilmu pengetahuan dewasa ini semakin pesat terutama dalam bidang teknologi, hal ini mengakibatkan menurunnya prosentase penggunaan tenaga manusia dalam bidang industri.

Dengan ditemukannya mesin-mesin serta penggunaannya dalam industri telah mendesak fungsi dari tenaga manusia namun tetap memegang peranan yang cukup penting. Betapapun sempurnanya peralatan kerja, katakanlah hanya sebagai penekan tombol untuk menjalankan mesin, maka pabrik tersebut tiada artinya, tidak ubahnya seonggok besi tua yang menantikan saat kemusnahannya.

dengan variabel terikatnya (dependent) yaitu Kinerja Pegawai (Y) sehingga dapat diperoleh hubungan yang signifikan atau hubungan yang tidak signifikan antara variabel bebasnya. Data yang sudah didapat kemudian diolah menggunakan program SPSS Versi 25 


\section{Hasil Penelitian dan Pembahasan}

1. Secara Simultan Pada tabel output diatas nilai $\mathrm{F}$ diperoleh sebesar 181,561 dengan signifikansi 0,000. Ini berarti model regresi ini layak untuk digunakan. Karena tingkat signifikansi lebih kecil dari 0,05, dan Fhitung lebih besar daripada $F$ tabel 181,561>2,43 sehingga dapat dikatakan bahwa mental, gaji, kesempatan promosi, kondisi kerja dan kesesuaian pribadi pekerja berpengaruh secara simultan dan signifikan terhadap kinerja Pegawai kantor pelayanan pajak muara teweh

2. Uji Analisis dilakukan Secara parsial menggunakan Uji t

1. Mental (X1), variabel mental berpengaruh signifikan secara parsial terhadap variabel kinerja Pegawai Kantor pelayanan pajak muara teweh

2. Gaji (X2), variabel gaji berpengaruh signifikan secara parsial terhadap variabel kinerja Pegawai Kantor pelayanan pajak muara teweh
3. kesempatan promosi (X3), variabel kesempatan promosi berpengaruh signifikan secara parsial terhadap variabel kinerja Pegawai Kantor pelayanan pajak muara teweh

4. Kondisi Kerja (X4), variabel kondisi kerja berpengaruh signifikan secara parsial terhadap variabel kinerja Pegawai Kantor pelayanan pajak muara teweh

5. Kesesuaian pribadi pekerja (X5), variabel Kesesuaian pribadi pekerja berpengaruh signifikan secara parsial terhadap variabel kinerja Pegawai Kantor pelayanan pajak muara teweh

3. Variabel yang lebih dominan dalam penelitian ini dari hasil uji analisis menggunakan SPSS Versi 25 ialah kesempatan promosi dapat dibuktikan dengan nilai koefisien regresi $(\beta)$ sebesar 0,639 dibandingkan nilai koefisien regresi variabel lainnya.

\section{Kesimpulan} bermanfaat

Pada bagian ini akan disimpulkan hasil penelitian yang telah dilakukan yang dianggap bagi Pegawai kantor pelayanan pajak muara teweh. Penelitian ini mencoba meneliti mengenai pengaruh mental, gaji, kesempatan promosi, kondisi kerja dan kesesuaian pribadi pekerja terhadap kinerja Pegawai kantor pelayanan pajak muara teweh. Berdasarkan uraian dan penjelasan yang telah dikemukakan pada bab-bab sebelumnya, maka dapat ditarik kesimpulan sebagai berikut :

1. Secara Simultan variabel mental, gaji, kesempatan promosi, kondisi kerja dan

\section{Saran}

Untuk mencapai tujuan kantor pelayanan pajak muara teweh terhadap kesesuaian pribadi pekerja berpengaruh signifikan terhadap kinerja Pegawai kantor pelayanan pajak muara teweh.

2. Secara mental, gaji, kesempatan promosi, kondisi kerja dan kesesuaian pribadi pekerja berpengaruh signifikan terhadap kantor pelayanan pajak muara

3. Variabel yang lebih dominan dari penelitian ini ialah kesempatan promosi hal itu terbukti pada uji hipotesis dominan dan dibuktikan dari nilai Signifikansi dari masing-masing variabel.

kinerja pegawai ada beberapa saran yang ingin disampaikan sebagai berikut : 
1. kepada kantor pelayanan pajak muara teweh untuk selalu menjaga standar operasi instansi yang telah ditetapkan, hal ini dikarenakan segala sesuatu yang terjadi akan sesuai dengan apa yang dilakukan, instansi dapat menjaga kinerja nya yaitu dengan meningkatkan mental, gaji, kesempatan promosi, kondisi kerja dan kesesuaian pribadi pekerja pada kinerja pegawai kantor pelayanan pajak muara teweh

2. Disarankan kepada kantor pelayanan pajak muara teweh untuk selalu memperhatikan pegawai pada kantor pelayanan pajak muara teweh, pegawai merupakan dasar utama dalam segala pekerjaan, dengan menjaga pegawai maka

\section{Daftar Pustaka}

Anthony, Robert N; Dearden, John dan Bedford, Norton M, alih Bahasa Agus Maulana, Sistem Pengendalian Manajemen. Edisi-6; Binarupa Aksara, 1992.

Arikunto, Suharsimi, Prof. Dr., Management Penelitian, Edisi Baru, PT. Rineka Cipta, Jakarta 1998.

Azwar, Saefuddin, Sikap Manusia, Teori dan Pengukurannya, Edisi II, Pustaka Pelajar, Yogyakarta, 1995.

Abraham Nurul Fajri, Hamidah Nayati Utami, Ika Ruhana. (2015). Pengaruh Promosi Terhadap kepuasan Kerja dan Prestasi Kerja Karyawan,. 29(1). 67-76. Jurnal Administrasi Bisnis (JAB)

Aris Ananta, 1990, Landasan Ekonomitrika, Bagian Penerbit PT. Gramedia, Jakarta. sama saja dengan menjaga kinerja yang telah dihasilkannya.

3. Untuk penelitian di masa yang akan datang sebaiknya memperluas variabel dan pengukuran variabel penelitian sehingga dapat lebih meningkatkan kinerja pegawai kantor pelayanan pajak muara teweh dan Diharapkan penelitian selanjutnya dapat mengkaji lebih dalam tentang variabel yang ada dalam penelitian ini yang mana masing - masing variabel saling berpengaruh terhadap kinerja pegawai secara simultan pada kantor pelayanan pajak muara teweh agar diperoleh gambaran yang lebih lengkap lagi sehingga diharapkan hasil penelitian yang akan datang lebih sempurna dari penelitian ini.

Baharuddin dan Moh. Makin, Manajemen Pendidikan Islam, (Malang: UINMaliki Press, 2010)

Dessler, Gary, Manajemen Sumber Daya Manusia; Human Resource Management 7e, Penerbit PT. Prenhallindo, Jakarta,1997.

Erickson, B.H., Nosanchuk, T.A., Memahami Data; Statistika untuk Ilmu Sosial, Penerbit McGraw-Hill Ryerson Ltd., Toronto, Canada, 1977, Alih Bahasa LP3ES, Anggota IKAPI, Jakarta 1987.

Fuady, Munir, S.H., M.H., LL.M., Hukum Bisnis; Dalam Teori dan Praktek Buku Ketiga, Penerbit PT. Citra Aditya Bakti, Bandung, 1994.

Has, A. Sanusi, Dasar-dasar Pernologi, Rasanta, Jakarta, 1994.

Kerlinger, Fred N. and Elazar J. Pedhazur, 1990, Foundation of Multiple 
Regresion Analysis, Holt, Rinehart \& Winston Inc, New York.

Kotler, Philip, 1991, Marketing Management, Analysis, Planing Implementation and Control, Edisi VII Prentice Hall Inc, Alih Bahasa Adi Zakaria Afif, Perencana Implementasi dan Pengendalian Buku I dan Buku II Edisi VII, Lembaga Penerbit Fakultas Ekonomi Universitas Indonesia, Jakarta 1993.

Lucas da Costa, 1993, Analisis Pengaruh Faktor-faktor dan Budaya Terhadap Tingkat Excelence, Studi kasus Pada Perusahaan Penerbit Surat Kabar Jawa Pos Surabaya, Tesis Universitas Airlangga Surabaya.

Paramita, Budhi. Struktur Organisasi di Indonesia. Jakarta: Lembaga Penerbit Fakultas Ekonomi Universitas Indonesia, 1985

Pearce \& Robinson, Strategic Management, Formulasi, Implementasi dan Pengendalian, Alih Bahasa Ir. Agus Maulana, MM, Bina Rupa Aksara, Jakarta, 1997.

Reksohardiprojo, Sukanto, Dasar-dasar Manajemen, Ed. 5. Yogyakarta: BPFE, 1992

Rahmat Hilmi, Anthonius J. Karsudjono, (2019). Pengaruh Tempat Dan Promosi Terhadap Pembelian Pada Ukhuwahmart Banjarmasin, 6(1), 42-60. Jurnal Komunikasi Bisnis dan Manajemen

Rencana Strategis Pembangunan, Direktorat Jendral

Pemasyarakatan
Departemen Hukum dan Perundang-undangan R.I., Jakarta 2000.

Robbins, Stehen P, Teori Organisasi : Struktur, Desain dan Aplikasi, Alih bahasa Yusuf Udaya, Lic, Ec. Jakarta: Arcan, 1995

Robins, Stepen P., Perilaku Organisasi, Konsep, Kontraversi dan Aplikasi, Alih Bahasa, Hadiana Pudjaatmaka, PT. Prehallindo, Jakarta, 1996.

Sudrajat, M. SW, 1996 Mengenal Ekonomitrika Pemula, Penerbit Armico, Bandung.

Sunarjo, 1992, Analysis Regresi Ganda dan Korelasi Parsial, Makalah, Disampaikan pada Penataran Metologi Penelitian Statistika dan Komputer Tingkat Menengah, Lembaga Pusat Penelitian Universitas Airlangga Surabaya.

Siagian, Sondang P., Peranan Staf dalam Manajemen, Cet. 18. Jakarta : Gunung Agung.

Suwarsono, Manajemen Strategik; Konsep dan Kasus, Penerbit Akademi Manajemen Perusahaan YKPN, Jl. Langensari 45 Balapan, Yogyakarta 55222, 1996.

Sudjana, Metode Statistika, Tarsito, Bandung. 1983.

Swastha DH, Baasu dan Handoko, T. Hani, 1990, Manajemen Pemasaran Analisa Perilaku Konsumen, Edisi Kedua, Liberty Yogyakarta. 
Uma, Sekaran, Research Methods for Busines, A Skill Building Approach, Second Edition, John Wiley \& Son, Singapore, 1992.

Sariyatul ilyana, Mahfud Sholihin. (2021). The Effect Of Incentive Leadership And Style Of Creative Performance, 36(1), 14-30. https://doi.org/10.22146/jieb.59893

Syaifuddin Fahmi. (2016). Pengaruh Stres Kerja dan Konflik Kerj Terhadap Semangat Kerja Karyawan pada PT. Omega Mas Pasuruan, 12(3), 107-116.

https://dx..doi.org/10.21067/jem.v1 $\underline{2 \mathrm{i} 3.1462}$ 